\title{
Seed type, habitat and time of day influence post-dispersal seed removal in temperate ecosystems
}

\author{
Katja Wehner $^{\text {Corresp., } 1}$, Lea Schaefer ${ }^{1}$, Nico Bluethgen $^{1}$, Karsten Mody $^{1}$ \\ ${ }^{1}$ Ecological Networks, Technische Universität Darmstadt, Darmstadt, Germany \\ Corresponding Author: Katja Wehner \\ Email address: kdwehner@gmx.de
}

Seed survival is of great importance for the performance of plant species and it is strongly affected by post-dispersal seed removal by either different animals such as granivorous species and secondary dispersers or abiotic conditions such as wind or water. The success of post-dispersal seed removal depends on seed specific traits including seed size, the presence of coats or elaiosomes, the mode of seed dispersion, and on the habitat in which seeds happen to arrive. In the present study we asked how seed traits (dehulled vs. intact; size; dispersal mode), habitat (forest vs. grassland), and time of day (night vs. day) influence post-dispersal seed removal of the four plant species Chelidonium majus, Lotus corniculatus, Tragopogon pratensis and Helianthus annuus. Seed removal experiments were performed in three regions in Hesse, Germany. The results showed different, inconsistent influences of time of day, depending on habitat and region, but consistent variation across seed types. C. majus and dehulled $H$. annuus seeds had the fastest removal rates. The impact of the habitat on post-dispersal seed removal was very low, only intact $H$. annuus seeds were removed at significantly higher rates in grasslands than in forests. Our study demonstrates consistent differences across seed types across different habitats and time: smaller seeds and those dispersed by animals had a faster removal rate. It further highlights that experimental studies need to consider seeds in their natural form to be most realistic. 
2

3 Seed type, habitat and time of day influence post-dispersal seed removal in temperate

4 ecosystems

5

6 Katja Wehner*, Lea Schäfer, Nico Blüthgen, Karsten Mody

7

8 Ecological Networks, Technische Universität Darmstadt, Schnittspahnstraße 3, 64287

9 Darmstadt, Germany

10

$11 *$ Corresponding author: Katja Wehner, kdwehner@gmx.de

12 


\section{Abstract}

14 Seed survival is of great importance for the performance of plant species and it is strongly affected by post-dispersal seed removal by either different animals such as granivorous species and secondary dispersers or abiotic conditions such as wind or water. The success of postdispersal seed removal depends on seed specific traits including seed size, the presence of coats or elaiosomes, the mode of seed dispersion, and on the habitat in which seeds happen to arrive. In the present study we asked how seed traits (dehulled vs. intact; size; dispersal mode), habitat (forest vs. grassland), and time of day (night vs. day) influence post-dispersal seed removal of the four plant species Chelidonium majus, Lotus corniculatus, Tragopogon pratensis and Helianthus annuus. Seed removal experiments were performed in three regions in Hesse, Germany. The results showed different, inconsistent influences of time of day, depending on habitat and region, but consistent variation across seed types. C. majus and dehulled H. annuus seeds had the fastest removal rates. The impact of the habitat on post-dispersal seed removal was very low, only intact $H$. annuus seeds were removed at significantly higher rates in grasslands than in forests. Our study demonstrates consistent differences across seed types across different habitats and time: smaller seeds and those dispersed by animals had a faster removal rate. It further highlights that experimental studies need to consider seeds in their natural form to be most realistic.

Keywords: seed traits, post-dispersal seed removal, seed predation, secondary seed dispersal, temperate ecosystem, seed type, elaiosomes, seed coat. 


\section{Introduction}

Seed dispersal, survival and germination are crucial for plant reproduction. Whereas seed dispersal depends on seed size, dispersal mode, and annual seed production (Lambert \& Champman, 2005), seed survival is additionally affected by post-dispersal seed removal. In general, the term post-dispersal seed removal includes both seed predation and secondary seed dispersal (Vander Wall, Kuhn \& Beck, 2005). For most plant species, the relative rate of predation (seeds that are digested by granivorous animals) versus dispersal (seeds that are consumed or removed but survive and germinate) is unknown (Vander Wall, Kuhn \& Beck, 2005). Seed predation can limit the population growth of certain plant species (Menalled et al., 2000), and it varies considerably due to different factors (Hulme, 1994), including habitat (Notman et al., 1996; Holl \& Lulow, 1997), microhabitat (Manson \& Stiles, 1998), seed species (Borchert \& Jain, 1978), seed burial (Hulme \& Borelli, 1999) and seed density (Myster \& Pickett, 1993). By feeding on seeds, granivores influence plant species diversity (Schupp, 1988), plant community structure (Brown \& Heske, 1990) and patterns of plant recruitment (Borchert \& Jain, 1978).

Besides post-dispersal seed predation, secondary seed dispersal also determines the performance of a plant, e.g. by reducing seed and seedling mortality near the parent, or by carrying seeds to suitable microhabitats for establishment and growth (Howe \& Smallwood, 1982; Meyer et al., 2017). Although seed predation is a common fate of seeds encountered by granivores, a number of animal groups transport seeds to microsites that favor seedling establishment; often up to half of the removed seeds are dispersed and germinate (Vander Wall, Kuhn \& Beck, 2005). In this case, seed removal is considered to be a mutualistic interaction between plants and animals (Bond, 1994) because seed dispersal benefits plants by reducing 
59 density-dependent seed and seedling mortality (Harms et al., 2000). Furthermore, seed dispersal

60 reduces competition with the parent plant and allows the exploitation of suitable new habitats

61 (Meyer et al., 2017), which is an important process in the reproductive cycle (Vander Wall \&

62 Longland, 2004).

63 Many animal groups such as rodents (Forget \& Milleron, 1991), birds (Levey et al., 2005),

64 ants (Bond, 1983; Peters, Oberrath \& Böhning-Gaese, 2003), dung beetles (Andresen, 2002) and

65 carabids (Brust \& House, 1988), as well as wind (Tackenberg, Poschold \& Bonn, 2003) and

66 water (Kowarik \& Säumel, 2008) can move seeds after primary dispersal from the mother plant.

67 Secondary dispersal by ants is well known and some plants produce seeds with lipid rich

68 appendages (elaiosomes) that are highly attractive to ants and facilitate dispersal (Handel \&

69 Beattie, 1990).

70 In many removal studies, easily obtainable dehulled sunflower seeds are used (e.g., Meyer et

71 al., 2017). As dehulled seeds are rarely found in nature, this study attempts to clarify the effect of

72 the presence of seed coats on seed removal. One of the main functions of the seed coat is the

73 protection of the embryo against mechanical injuries (Souza \& Marcos-Filho, 2001).

74 Furthermore, seed size affects seed dispersal and has strong effects on the range of potential

75 granivores (Xiao, Zhang \& Wang, 2005). In rodent-dispersed fagaceous species, for example, the

76 distribution range of seeds increased with seed size, and larger seeds were more often recaptured

77 after consumption than smaller seeds (Xiao, Zhang \& Wang, 2005).

78 The occurrence and activity of seed consuming animals may vary between different habitats

79 (Webb \& Willson. 1985; Lindgren, Lindborg \& Cousins, 2018) and times of day (Miranda-

80 Jácome \& Flores, 2018). Studies on post-dispersal seed removal in different habitats revealed

81 significant differences in the proportion of total seeds remaining in open pastures, forests and 
82 beneath isolated pasture trees, and different seed species suffered differently in different habitats

83 (Holl \& Lulow, 1997). Seed-feeding animals such as ants, rodents and birds have a great

84 potential to influence seed dynamics (Hulme, 1998). Since their occurrence and abundances differ among habitats, their influence on seed removal may differ accordingly.

The time of day may also influence post-dispersal seed predationby temporal differences in foraging activities of seed predators. These differences may develop to reduce competition between different seed predators (Brown et al., 1975), to reduce enemy pressure (Manson \& Stiles, 1998), or to take advantage of favorable abiotic conditions (Whitford et al., 1981). In the present study we asked how seed traits (dehulled vs. intact; size; dispersal mode), habitat (forest vs. grassland), and time of day (night vs. day) influence post-dispersal seed removal. We did not distinguish between predation and dispersal since seed removal has not been tracked, but seed predators/dispersers have been incidentally observed. As seed predators and seed dispersers differ in their preferences for seed size (Brown et al., 1975; Reader, 1993; Larios et al, 2017) and in spatial and temporal foraging activities, we expected that seed traits, habitat, and time of day contribute to variation in seed removal rates.

To examine the effects of seed traits, habitat, and time of day on post dispersal seed removal, we used the three native plant species Chelidonium majus L., Lotus corniculatus L. and Tragopogon pratensis L., and the crop and ornamental plant Helianthus annuus L. These plant species were chosen to represent a large variation in seed size and dispersal mode. For $H$. annuиs, we used intact fruits (intact cypselae consisting of kernel surrounded by seed coat), and in addition dehulled kernels. H. annuus seeds are generally dispersed by animals which usually use them as food and can also be blown to different localities by wind (Cummings \& Alexander, 2002). The seeds of $T$. pratensis are generally wind-dispersed with a feathery pappus as flying 
105 organ (Casseau et al., 2015). C. majus seeds are small and associated with lipid rich appendages

106 (elaiosomes) that are highly attractive to ants (Handel \& Beattie, 1990). Seeds of L. corniculatus

107 are small and catapulted up to five meters by a longitudinally dehiscent fruit (Jones \&

108 Turkington, 1986).

109 We expected post-dispersal seed removal to differ with seed traits: smaller seeds (C. majus,

110 L. corniculatus) should be removed faster than larger seeds (H. annuus), and we expected a

111 lower removal of intact compared to dehulled sunflower (H. annuus) seeds due to the protective

112 properties of the seed coat. Concerning the mode of seed-dispersal, we expected that seeds that

113 are typically wind-dispersed (T. pratensis) are less affected by secondary seed dispersal via

114 animals than seeds with elaiosomes (C. majus), which are generally considered being ant-

115 dispersed (Handel \& Beattie, 1990; Fornara \& Dalling, 2005). We further expected a higher seed

116 removal rate in grasslands as compared to forests due to higher abundances of granivores. In

117 both habitats we expected that seed removal at different times of the day would be different

118 depending on the seed type: large seeds consumed by nocturnal rodents $(H$. annuus $)$ should be

119 removed faster at night, while small seeds consumed by diurnal ants (C. majus) should be

120 removed faster during the day.

121

122 Materials \& Methods

123 Study area

124 Our study was conducted in the South of Hesse, Germany, in June and July 2018. Since we 125 were interested in comparing the two common habitats forest and grasslands, we selected forest 126 (coniferous and deciduous) and grassland sites in each of three regions which are $20 \mathrm{~km}$ apart on 127 average: Darmstadt, Oberzent/Airlenbach and Bad König/Zell (see Supplement 1 for site 
128 coordinates). In Darmstadt, all grassland sites are meadows that are mown once or twice per

129 year. Forest sites are recreational areas comprising only a moderate amount of forestry; they are

130 mixed forests with native deciduous trees. In Airlenbach, grasslands are intensively used: they

131 are mown three times a year and fertilized with cattle manure. Forest sites are recreational areas

132 comprising mixed and coniferous stands. In Zell, grassland use is not agricultural but sites are

133 mown once a year to avoid bush encroachment. Sites are located close to the river Mümling and 134 regularly flooded. Forest sites are recreational deciduous mixed forests.

Plant species and seed parameters

137 Four plant species with different dispersal modes and seed traits were used:

138 a) Chelidonium majus; small seeds with elaiosomes, dispersed by arthropods

139 b) Lotus corniculatus; small seeds lacking elaiosomes, dispersed by longitudinally dehiscent 140 fruits

141 c) Tragopogon pratensis; medium sized seeds with a pappus, wind dispersed

d) Helianthus annuus; large seeds dispersed by animals (birds, arthropods) and wind, intact (with seed coat) and dehulled seeds were compared.

Accordingly, five seed types were tested in total, represented by a single seed species or in case of $H$. annuus two variants of seed species. All seeds were purchased at Rieger-Hofmann $146 \mathrm{GmbH}$, Blaufelden-Raboldshausen, Germany. For each seed type, the dry mass was quantified 147 by measuring the mass of ten randomly selected seeds and the mean and standard deviation for 148 each seed type was calculated: $C$. majus $=0.7 \pm 0.0 \mathrm{mg}$, L. corniculatus $=1.1 \pm 0.1 \mathrm{mg}, T$.

149 pratensis $=7.9 \pm 2.5 \mathrm{mg}$, H. annuus intact $=83.1 \pm 18.9 \mathrm{mg}$, H. annuus dehulled $=50.4 \pm 7.0$ $150 \mathrm{mg}$. 
152

154

155

156

157

158

159

160

161

162

163

164

165

166

167

168

169

170

171

172

173

Study 1: Seed removal, habitat and seed type

We compared the seed removal of different seed types in two forest and two meadow sites in Darmstadt, and one meadow and one forest site in Airlenbach. For each site, five subplots were established $10 \mathrm{~m}$ away from each other. We checked plates for the number of remaining seeds at regular intervals of 60 min for ten hours in Airlenbach and for seven hours in Darmstadt to investigate the removal rate and after 48 hours for total removal. We counted a seed as removed when it had left the plate; thus, we recorded a seed as present, when it had been removed from its well, but was still lying on the plate (Meyer et al., 2017). Based on the number of seeds remaining after different time intervals, we calculated the percentage of removed seeds. While counting seeds at different time intervals, incidental observations on seed predators/dispersers (e.g., ants, slugs, other arthropods) were recorded.

A total of 25 seeds of the same seed type were offered simultaneously within a subplot on a $12 \mathrm{~cm} \times 12 \mathrm{~cm} \times 0.5 \mathrm{~cm}$ (length x width x height) gray plastic plate. The plate contains 25 evenly spaced wells for seed exposure, each well containing a single seed. For each seed type a separate plate was used; this method is consistent with standard protocols for ecosystem process assessments (Meyer et al., 2017). Seed plates were haphazardly placed flat on the ground approximately in the center of the site by carefully flattening the groundcover.

\section{Study 2: Seed removal and time of day}

We investigated the influence of time of day (day vs. night) on seed removal in three different regions (Darmstadt, Airlenbach and Zell). In total, we tested 16 different study sites per habitat: six grasslands and six forests in Darmstadt, six grasslands and six forests in Airlenbach 
174 and four grasslands and four forests in Zell. In each study site, we tested four different seed

175 types: C. majus, L. corniculatus, intact H. annuus and dehulled H. annuus seeds. As in study 1 ,

17625 seeds of the same seed type were offered simultaneously on a grey plastic plate. Seeds were

177 left in the field for 12 hours during the day. After 12 hours, the remaining seeds were quantified.

178 Afterwards, the plates were refilled with new seeds. To avoid positional effects, the plates were

179 set up 10 m away from the day plot; all plate locations were chosen haphazardly. The seed plates

180 were left in the field for another 12 hours, covering a period of reduced light and the night. As

181 the 12-hours interval did not perfectly match the actual day- and night-period, observations

182 during the "daytime" assessments always reflected daytime conditions, but the observations

183 during the "nighttime" assessments also included evening and morning (twilight) conditions.

184 This means that species that depend on light and higher temperatures were only recorded during

185 the daytime assessments, but the species recorded during the nighttime assessments may also

186 include species that are active at the transition between night and day. After 12 hours, remaining

187 seeds were quantified. Removal rates were calculated as percentages.

Statistical analysis

Study 1: Seed removal, habitat and seed type

All collected data were analyzed with R 3.5.2 (R Core Team 2018). Data were checked for normal distribution and $\log (\mathrm{x}+1)$ or square root transformed to increase homogeneity of variances if necessary.

To test the effect of seed type on seed removal over time in different habitats (forest vs. grassland), we first compared the proportional removal of seeds after $48 \mathrm{~h}$ (Meyer et al., 2017). 
197 seeds removed after $48 \mathrm{~h}$. Results were analyzed using a linear mixed-effect model (lmer) with $R$

198 as dependent variable, and region, habitat and seed type as independent variables, including the

199 interaction between habitat and seed type. Plots were included as random factor, individual

200 effects were analyzed by one-way ANOVA included in the car package (Fox \& Weisberg, 2019).

201 We additionally investigated seed removal over time using linear regressions; first, we

202 compared the fit of linear versus non-linear models using Integrated Nested Laplace

203 Approximation (Inla) and results showed linear models to fit best. For each seed type, seed

204 removal (dependent variable) was plotted versus time (predictor). Effects were analyzed using a

205 linear mixed-effect model (lmer) with square root transformed number of seeds removed as

206 dependent variable and region, habitat, time and seed-type as independent variables, including

207 interaction terms between variables. Plots were included as random factor (see Supplement 2 for

208 raw data).

209

210

Study 2: Seed removal and time of day

211 To evaluate the influence of time of day (day vs. night), we also used a linear mixed-effect

212 model (lmer) with time of day, habitat and region as independent variables (including the

213 interaction terms of the variables) and plots as random factor. One-way ANOVA was calculated

214 individually for each seed type per habitat and region (see Supplement 3 for raw data).

215

216 Results

217 Study 1: Seed removal, habitat and seed type

218 Seed removal after 48 hours differed significantly across seed types but not among regions

219 and only slightly among habitats; however, there was no interaction between habitat and seed 
220 type (Fig. 1, Table 1). Both in forests and in grasslands, C. majus and dehulled H. annuus seeds

221 were often removed entirely, and their removal was significantly higher than for L. corniculatus,

222 intact $H$. annuus and T. pratensis seeds; the latter three species did not differ significantly (Fig.

223 1). Removal of L. corniculatus, C. majus, dehulled H. annuus and T. pratensis seeds did not

224 differ significantly between habitats, whereas seeds of intact $H$. annuus were removed faster in

225 grasslands than in forests.

226 For each seed type in each region, seed removal increased continuously over time (Fig. 2,

227 Table 2). In both regions and both habitats, C. majus and dehulled H. annuus seed removal was

228 fastest, corresponding to the results after 48 hours. With one exception (forest, Darmstadt), $C$.

229 majus seed removal had the highest increase over time, while the removal of dehulled H. annuus

230 seeds was fastest in forests in Darmstadt. However, removal rates changed in time with habitat

231 and seed type (Table 2); e.g., T. pratensis was removed at higher rates in grasslands in Darmstadt

232 but in forests in Airlenbach.

233

234 Study 2: Seed removal and time of day

235 Post-dispersal seed removal at different times of day significantly differed with habitat and

236 region (Table 3). The removal of C. majus was higher at night in grasslands in Darmstadt and

237 forests in Zell, but more pronounced during the day in grasslands in Airlenbach and Zell (Fig.

238 3B). Night removal of dehulled H. annuus was higher in grasslands in Darmstadt (Fig. 3C) and

239 night removal of intact H. annuus was more pronounced in forests in Zell (Fig. 3D).

240 In general, seed removal of L. corniculatus was generally low (Fig. 3A). C. majus was

241 removed at higher rate at night in grasslands in Darmstadt and in forests in Zell, whereas day-

242 removal seemed to be more pronounced in forests in Airlenbach and grasslands in Zell (Fig. 3B). 
243 The removal of dehulled H. annuus was generally low in Darmstadt, but higher in grasslands in

244 Airlenbach and forests in Zell (Fig. 3C). Intact H. annuus was even less removed than dehulled

245 seeds, but tended to be removed at higher rate at night (Fig. 3D).

247 Discussion

248 Study 1: Seed removal, habitat and seed type

249 Post-dispersal seed removal after $48 \mathrm{~h}$ differed across plant species. In both habitats, forest

250 and grassland, seed removal of $C$. majus and dehulled H. annuus seeds was significantly higher 251 than the removal of L. corniculatus, intact H. annuus and T. pratensis seeds.

252 In contrast to L. corniculatus, C. majus seeds are myrmecochorous because of the presence 253 of elaiosomes (Pemberton \& Irving, 1990; Peters et al., 2003). These lipid-rich appendages are 254 attractive to many ant species and promote burial and dispersal (Hughes et al., 1994; Fischer et 255 al., 2008). Since the abandoned seeds maintain their ability to germinate, seeds are dispersed 256 effectively (Kjellsson, 1985; Gorb \& Gorb; 2003). We observed that ants removed seeds of both 257 C. majus and L. corniculatus, but preferred seeds of C. majus.

258 Removal of dehulled H. annuus was significantly higher than of natural, intact H. annuus 259 seeds. This result mirrors the physical protection of the nutritional seed components by the seed 260 coat (Souza \& Marcos-Filho 2001) that are apparent in dehulled seeds, and may additionally be 261 driven by increased energy requirements for handling such intact seeds (Pyke et al., 1977). In our

262 study, we observed that ants and slugs consumed dehulled but ignored intact seeds, which was 263 most probably directly related to the accessibility of the seed material in dehulled seeds. In 264 addition to physical protection, dehulled seeds may produce more attractive odors, resulting in 
265 higher seed predation by granivores guided by olfactory cues (Jaganathan, 2018; Vander Wall, 266 1998).

267 Tragopogon pratensis seeds are attached to a pappus and are primarily wind-dispersed

268 (Casseau et al., 2015). Thus, we expected the removal by animals to be of minor importance. As

269 predicted, removal of $T$. pratensis seeds was low and no T. pratensis seed removal by animals

270 was observed (but predators/dispersers were not monitored over time). However, secondary seed

271 dispersal by animals may be highly relevant also for primarily wind-dispersed plant species (der

272 Weduwen \& Ruxton, 2019), e.g., when wind-dispersed pines (Pinus spp.) are dispersed by

273 scatterhoarding rodents (Vander Wall, 2003).

274 In summary, the results of our study show that post-dispersal seed removal depends on seed

275 specific traits that differ among the seed species we used. Smaller seeds (C. majus, $L$.

276 corniculatus), seeds that are more easily accessible (dehulled H. annus) and those dispersed by

277 animals (C. majus) are removed faster than large (intact H. annuus), protected (intact H. annuus)

278 or those seeds that depend on abiotic conditions for dispersal (T. pratensis). Since C. majus were

279 removed at the highest rate, the presence of elaiosomes may have strengthened the advantage of

280 being small. Thus, C. majus may have achieved an increased germination probability in new

281 habitats away from the mother plant. However, the variation of seed traits used in this study may

282 not be exclusively causal for the observed results owing to the potential collinearity with other

283 unmeasured traits.

284 Typically, habitat (forest vs. grassland) had no effect on seed removal, although removal of 285 intact $H$. annuus was higher in grasslands. In general, as seed predators may differ in spatial 286 foraging patterns (Brown et al., 1975), many studies indicate a relevant effect of habitat type on 287 seed removal concerning both microhabitats (Notman et al., 1996; Ji-Qi \& Zhi-Bin, 2004) and 
288 forest and grassland sites (Holl \& Lulow 1997). Previous studies comparing levels of seed

289 removal in early- and late-successional habitats have shown variable results: a few studies

290 indicated that seed predation is higher in early than in mature successional habitats (Uhl, 1987;

291 Hammond, 1995) whereas other studies reported opposite results (Aide \& Cavelier, 1994;

292 Osunkoya, 1994). Other studies showed that the habitat with the highest level of seed predation

293 varies with seed species (Willson \& Whelan, 1990; Whelan et al., 1991; Holl \& Lulow, 1997).

294 However, the effect of habitat on post-dispersal seed removal seems inconsistent and may

295 depend on seed type and predator. Therefore, a comprehensive seed study of the plant

296 community in different habitats and seed predators therein may be necessary to solve that

297 problem.

298

299

Study 2: Seed removal and time of day

300 The effects of time of day on post dispersal seed removal of seed types differed with habitat 301 and region. Contrary to this finding, several former studies indicated that seed predators differ not only in their preferences for seed types but also in their temporal patterns of foraging activities (Brown et al., 1975). Granivorous rodents are mainly nocturnal (Abramsky, 1983; Miller, 1994; Xiao, Zhand \& Wang, 2005), whereas harvester ants are mostly diurnal (Abramsky, 1983; Díaz, 1992), as ectothermy of ants renders foraging activities temperaturedependent (Whitford et al., 1981; MacKay \& MacKay, 1989). Thus, we expected that time of day influences seed removal, and that removal of myrmecochorous C. majus seeds was higher at day which was true for grassland sites in Airlenbach and Zell. Contrary to this expectations, removal of $C$. majus seeds was even higher at night in grasslands in Darmstadt and forests in

310 Zell. Possibly, unusually very high temperatures in the summer 2018, may have shifted foraging 
311 activities of diurnal granivores to the early morning and late evening hours, which were covered

312 by the nighttime assessments.

313

\section{Conclusion}

315 Our study demonstrates that seed type and - to a lesser extent - habitat influence seed

316 removal. With regard to studies on seed removal, our studies emphasizes that the traits of the

317 used seeds, like in our case the comparison of intact and dehulled seeds, may have strong effects

318 on the outcome of experiments. Furthermore, differences between day and night removal should

319 be considered.

320

321 Acknowledgements

322 We thank E. Schäfer for providing the trial areas in Airlenbach and N. Simons for supporting the 323 statistical analyses. We are further grateful to two anonymous reviewers for very valuable 324 comments on an earlier draft of the manuscript.

\section{References}

327 Abramsky Z. 1983. Experiments on seed predation by rodents and ants in the Israeli desert.

$328 \quad$ Oecologia 57:328-332.

Aide TM, Cavelier J. 1994. Barriers to lowland tropical forest restoration in the Sierra Nevada de

330 Santa Marta, Colombia. Restoration Ecology 2:219-229.

331 Andresen E. 2002. Dung beetles in a central Amazonian rainforest and their ecological role as

332 secondary seed dispersers. Ecological Entomology 27:257-270. 
333 Bond P. 1983. Seed dispersal by ants in shrublands of the Cape Province and its evolutionary

334 implications. South African Journal of Science 79:231-233.

335 Bond W. 1994. Do mutualisms matter? Assessing the impact of pollinator and disperser

336 disruption on plant extinction. Philosophical Transactions of the Royal Society London B

$337 \quad 344: 83-90$.

338 Borchert MI, Jain S. 1978. The effect of rodent seed predation on four species of California

339 annual grasses. Oecologia 33:101-113.

340 Brown JH, Grover JJ, Davidson DW, Lieberman GA. 1975. A preliminary study of seed

341 predation in desert and montane habitats. Ecology 56:987-992.

342 Brown JH, Heske EJ. 1990. Control of a desert-grassland transition by a keystone rodent guild.

$343 \quad$ Science 250:1705-1707.

344 Brust GE, House GJ. 1988. Weed seed destruction by arthropods and rodents in low-input

345 soybean agroecosystems. American Journal of Alternative Agriculture 3:19-25.

346 Casseau V, De Croon G, Izzo D, Pandolfi C. 2015. Morphologic and aerodynamic considerations

347 regarding the plumed seeds of Tragopogon pratensis and their implications for seed dispersal.

$348 \quad$ Plos One 10:e0125040.

349 Cummings CL, Alexander HM. 2002. Population ecology of wild sunflowers: effects of seed 350 density and post-dispersal vertebrate seed predators. Oecologia 130:274-280.

351 der Weduwen D, Ruxton GD. 2019. Secondary dispersal mechanisms of winged seeds: a review.

$352 \quad$ Biological Reviews 94:1830-1838.

353 Díaz M. 1992. Spatial and temporal patterns of granivorous ant seed predation in patchy cereal 354 crop areas of central Spain. Oecologia 91:561-568. 
355 Fischer RC, Richter A, Hadacek F, Mayer V. 2008. Chemical differences between seeds and

356 elaiosomes indicate an adaptation to nutritional needs of ants. Oecologia 155:539-547.

357 Fonara DA, Dalling JW. 2005. Post-dispersal removal of seeds of pioneer species from five

358 Panamanian forests. Journal of Tropical Ecology 21:79-84.

359 Forget P-M, Milleron T. 1991. Evidence for secondary seed dispersal by rodents in Panama.

$360 \quad$ Oecologia 87:596-599.

361 Fox J, Weisberg S. 2019. An R Companion to Applied Regression, Third edition. Sage,

362 Thousand Oaks CA. https://socialsciences.mcmaster.ca/jfox/Books/Companion/

363 Gorb E, Gorb S. 2003. The myrmecochorous syndrome. Seed Dispersal by Ants in a Deciduous

364 Forest Ecosystem. pp. 5-24, Springer.

365 Hammond D. 1995. Post-dispersal seed and seedling mortality of tropical dry forest trees after

366 shifting agriculture, Chiapas, Mexico. Journal of Tropical Ecology 11:295-313.

367 Handel SN, Beattie AJ. 1990. Seed dispersal by ants. Scientific American 263:76-83B.

368 Harms KE, Wright SJ, Calderón O, Hernández A, Herre EA. 2000. Pervasive density-dependent

369 recruitment enhances seedling diversity in a tropical forest. Nature 404:493.

370 Holl KD, Lulow ME. 1997. Effects of species, habitat, and distance from edge on post-dispersal

371 seed predation in a tropical rainforest. Biotropica 29:459-468.

372 Howe FH, Smallwood J. 1982. Ecology of seed dispersal. Annual Review of Ecology and

$373 \quad$ Systematics 13:201-228.

374 Hughes L, Westoby M, Jurado E. 1994. Convergence of elaiosomes and insect prey: evidence

375 from ant foraging behaviour and fatty acid composition. Functional Ecology 8:358-365.

376 Hulme PE. 1994. Post-dispersal seed predation in grassland: its magnitude and sources of

377 variation. Journal of Ecology 82:645-652. 
378 Hulme PE, Borelli T. 1999. Variability in post-dispersal seed predation in deciduous woodland:

379 relative importance of location, seed species, burial and density. Plant Ecology 145:149-156.

380 Jaganathan GK. 2018. Crypsis hypothesis as an explanation for evolution of impermeable coats

381 in seeds is anecdotal. Ecological Research 33:857-861.

382 Ji-Qi L, Zhi-Bin Z. 2004. Effects of habitat and season on removal and hoarding of seeds of wild 383 apricot (Prunus armeniaca) by small rodents. Acta Oecologica 26:247-254.

384 Jones DA, Turkington R. 1986. Biological flora of the British ilses. No. 163 Lotus corniculatus L. Journal of Ecology 74:1185-1212.

386 Kjellsson G. 1985. Seed fate in a population of Carex pilulifera L. Oecologia 67:416-423.

387 Kowarik I, Säumel I. 2008. Water dispersal as an additional pathway to invasions by the 388 primarily wind-dispersed tree Ailanthus altissima. Plant Ecology 198:241-252.

389 Lambert JE, Champman CA. 2005. The Fate of Primate-dispersed Seeds: Deposition Pattern, 390 Dispersal Distance and Implications for Conservation. In: Forget PM, Lambert JE, Hulme PE, 391 Vander Wall SB, eds. Seed fate. Predation, Dispersal and Seedling Establishment. CABI 392 Publishing, Cambridge. pp 137-151.

393 Larios E, Búrquez A, Valenzuela G, Chesson P, Venable DL. 2017. Post-dispersal seed 394 predation in relation to selection on seed size in Dithyrea californica. Evolutionary Ecology $395 \quad$ Research 18:651-662.

396 Levey DJ, Bolker BM, Tewksbury JJ, Sargent S, Haddad NM. 2005. Effects of landscape 397 corridors on seed dispersal by birds. Science 309:146-148.

Lindgren J, Lindborg R, Cousins SA. 2018. Local conditions in small habitats and surrounding landscape are important for pollination services, biological pest control and seed predation.

$400 \quad$ Agriculture, Ecosystems \& Environment 251:107-113 
401 MacKay WP, MacKay EE. 1989. Diurnal foraging patterns of Pogonomyrmex harvester ants 402 (Hymenoptera: Formicidae). The Southwestern Naturalist 34:213-218.

403 Manson RH, Stiles EW. 1998. Links between microhabitat preferences and seed predation by 404 small mammals in old fields. Oikos 82:37-50.

405 Menalled FD, Marino PC, Renner KA, Landis DA. 2000. Post-dispersal weed seed predation in 406 Michigan crop fields as a function of agricultural landscape structure. Agriculture, Ecosystems 407 \& Environment 77:193-202.

408 Meyer ST, Leidinger JL, Gossner MM, Weisser WW. 2017. Handbook of field protocols for 409 using REFA methods to approximate ecosystem functions-Version 1.0.

410 Miller MF. 1994. Seed predation by nocturnal rodents in an African savanna ecosystem. African $411 \quad$ Zoology 29:262-266.

412 Miranda-Jácome A, Flores J. 2018. Effects of nurse plants and the granivore guild in the 413 associational susceptibility of seeds from the columnar cactus Pilosocereus leucocephalus. $414 \quad$ Journal of Arid Environments 151:9-14.

415 Myster RW, Pickett S. 1993. Effects of litter, distance, density and vegetation patch type on 416 postdispersal tree seed predation in old fields. Oikos 66:381-388.

417 Notman E, Gorchov DL, Cornejo F. 1996. Effect of distance, aggregation, and habitat on levels 418 of seed predation for two mammal - dispersed neotropical rain forest tree species. Oecologia $419 \quad$ 106:221-227.

420 Osunkoya OO. 1994. Postdispersal survivorship of north Queensland rainforest seeds and fruits: 421 Effects of forest, habitat and species. Australian Journal of Ecology 19:52-64.

422 Pemberton RW, Irving DW. 1990. Elaiosomes on weed seeds and the potential for 423 myrmecochory in naturalized plants. Weed Science 38:615-619. 
424 Peters M, Oberrath R, Böhning-Gaese K. 2003. Seed dispersal by ants: are seed preferences

425 influenced by foraging strategies or historical constraints? Flora-Morphology, Distribution, $426 \quad$ Functional Ecology of Plants 198:413-420.

427 Pyke GH, Pulliam HR, Charnov EL. 1977. Optimal foraging: a selective review of theory and 428 tests. The Quarterly Review of Biology 52:137-154.

429 R Core Team. 2018. R: A language and environment for statistical computing. R Foundation for 430 Statistical Computing, Vienna, Austria. ISBN 3-900051-07-0, URL http://www.R431 project.org/.

432 Reader RJ. 1993. Control of seedling emergence by ground cover and seed predation in relation 433 to seed size for some old-field species. Journal of Ecology 81:169-175.

434 Schupp EW. 1988. Seed and early seedling predation in the forest understory and in treefall gaps. 435 Oikos 51:71-78.

436 Souza FH, Marcos-Filho J. 2001. The seed coat as a modulator of seed-environment 437 relationships in Fabaceae. Brazilian Journal of Botany 24:365-375.

438 Tackenberg O, Poschlod P, Bonn S. 2003. Assessment of wind dispersal potential in plant $439 \quad$ species. Ecological Monographs 73:191-205.

440 Uhl C. 1987. Factors controlling succession following slash-and-burn agriculture in Amazonia. $441 \quad$ The Journal of Ecology 75:377-407.

442 Vander Wall SB. 1998. Foraging success of granivorous rodents: effects of variation in seed and 443 soil water on olfaction. Ecology 79:233-241.

444 Vander Wall SB. 2003. Effects of seed size of wind-dispersed pines (Pinus) on secondary seed 445 dispersal and the caching behavior of rodents. Oikos 100:25-34. 
446 Vander Wall SB, Kuhn KM, Beck MJ. 2005. Seed removal, seed predation, and secondary

447 dispersal. Ecology 86:801-806.

448 Vander Wall SB, Longland WS. 2004. Diplochory: are two seed dispersers better than one?

449 Trends in Ecology \& Evolution 19:155-161.

450 Webb SL, Willson MF. 1985. Spatial heterogeneity in post-dispersal predation on Prunus and

$451 \quad$ Uvularia seeds. Oecologia 67:150-153.

452 Whelan CJ, Willson MF, Tuma CA, Souza-Pinto I. 1991. Spatial and temporal patterns of

453 postdispersal seed predation. Canadian Journal of Botany 69:428-436.

454 Whitford WG, Depree DJ, Hamilton P, Ettershank G. 1981. Foraging ecology of seed-harvesting

455 ants, Pheidole spp. in a Chihuahuan desert ecosystem. American Midland Naturalist 105:159-

$456 \quad 167$.

457 Willson MF, Whelan CJ. 1990. Variation in postdispersal survival of vertebrate-dispersed seeds:

458 Effects of density, habitat, location, season, and species. Oikos 57:191-198.

459 Xiao Z, Zhang Z, Wang Y. 2005. The effects of seed abundance on seed predation and dispersal

460 by rodents in Castanopsis fargesii (Fagaceae). Plant Ecology 177:249-257.

461

462 Figure legends

463 Figure 1 Proportional seed removal of Lotus corniculatus, Chelidonium majus, dehulled and 464 intact Helianthus annuus and Tragopogon pratensis in forests (grey) and grasslands (white) 465 after 48 hours. Different letters above boxplots indicate significant differences between seed 466 types, significance levels beneath boxplots indicate differences between habitats, whiskers 467 denote range of data. The black box summarizes differences in seed traits. ns $=$ not

$468 \quad$ significant, $* *=\mathrm{p}<0.01,(*)=\mathrm{p}=0.05$ 
470 Figure 248 hours-timescale of seed removal of Lotus corniculatus, Chelidonium majus, dehulled 471 and intact Helianthus annuus and Tragopogon pratensis in forests (A) and grasslands (B) in

472 Darmstadt, and forests (C) and grasslands (D) in Airlenbach. Note the logarithmic scale of the $473 \quad \mathrm{x}$-axis. The black box summarizes differences in seed traits.

474

475 Figure 3 Removal of seeds of Lotus corniculatus (A), Chelidonium majus (B), dehulled (C) and 476 intact (D) Helianthus annuus at different times of day (day vs night) in forest and grassland 477 sites in Darmstadt, Airlenbach and Zell. Whiskers denote range of data, the black box summarizes differences in seed traits. $*=\mathrm{p}<0.05, * *=\mathrm{p}<0.02, * * * \mathrm{p}<0.01$.

479

480 Supplement 1. GPS coordinates of forest and grassland sites in Darmstadt, Airlenbach and Zell 481 in South Hesse, Germany. LoCo = Lotus corniculatus, ChMa = Chelidonium majus, dhHeAn $482=$ dehulled Helianthus annuus, inHeAn = intact Helianthus annuus.

484 Supplement 2. Raw data for study 1.

485

486 Supplement 3. Raw data for study 2. 


\section{Table 1 (on next page)}

Post-dispersal seed removal after 48 hours

Influence of seed type, habitat and region on post-dispersal seed removal after 48 hours, tested by a linear mixed-effects model on log +1 transformed data with subplots as random factor. 
1 Table 1 Influence of seed type, habitat and region on post-dispersal seed removal after 48 hours,

2 tested by a linear mixed-effects model on $\log +1$ transformed data with subplots as random factor.

3

\begin{tabular}{l|ccc} 
& Df & Chisq & p \\
\hline seed type & 4 & 152.247 & $<\mathbf{0 . 0 0 1}$ \\
habitat & 1 & 3.374 & 0.066 \\
region & 1 & 0.300 & 0.584 \\
habitat:seed type & 4 & 5.201 & 0.267
\end{tabular}

4 


\section{Table 2 (on next page)}

Post-dispersal seed removal over time

Influence of region, habitat, time and seed type on post-dispersal seed removal over time tested by a linear mixed-effects model on sqrt-transformed data with subplots as random factor. 
1 Table 2 Influence of region, habitat, time and seed type on post-dispersal seed removal over time

2 tested by a linear mixed-effects model on sqrt-transformed data with subplots as random factor.

3

\begin{tabular}{l|ccc} 
& DF & Chisq & p \\
\hline region & 1 & 3.923 & $\mathbf{0 . 0 4 7}$ \\
habitat & 1 & 2.797 & 0.094 \\
time & 1 & 550.026 & $<\mathbf{0 . 0 0 1}$ \\
seed type & 4 & 785.526 & $<\mathbf{0 . 0 0 1}$ \\
habitat*time & 1 & 3.959 & $\mathbf{0 . 0 4 7}$ \\
habitat*seed type & 4 & 10.282 & $\mathbf{0 . 0 3 6}$ \\
time*seed type & 4 & 57.48 & $<\mathbf{0 . 0 0 1}$ \\
habitat*time*seed type & 4 & 3.551 & 0.470
\end{tabular}

4 


\section{Table 3(on next page)}

Post-dispersal seed removal and daytime

Influence of day time, habitat and region on post-dispersal seed removal after 12 hours, tested by a linear mixed-effects model on sqrt-transformed data with subplots as random factor. 
1 Table 3 Influence of day time, habitat and region on post-dispersal seed removal after 12 hours,

2 tested by a linear mixed-effects model on sqrt-transformed data with subplots as random factor.

3

\begin{tabular}{l|ccc} 
& DF & Chisq & p \\
\hline day time & 1 & 0.806 & 0.369 \\
habitat & 1 & 0.732 & 0.392 \\
region & 2 & 5.382 & 0.068 \\
day time*habitat & 1 & 0.002 & 0.969 \\
day time*region & 2 & 3.476 & 0.176 \\
habitat*region & 2 & 4.963 & 0.083 \\
day time*habitat*region & 2 & 12.451 & $\mathbf{0 . 0 0 2}$
\end{tabular}

4 


\section{Figure 1}

Seed removal after 48 hours

Proportional seed removal of Lotus corniculatus, Chelidonium majus, dehulled and intact Helianthus annuus and Tragopogon pratensis in forests (grey) and grasslands (white) after 48 hours. Different letters above boxplots indicate significant differences between seed types, significance levels beneath boxplots indicate differences between habitats, whiskers denote range of data. The black box summarizes differences in seed traits. ns $=$ not significant, $* *=$ $p<0.01,(*)=p=0.05$ 


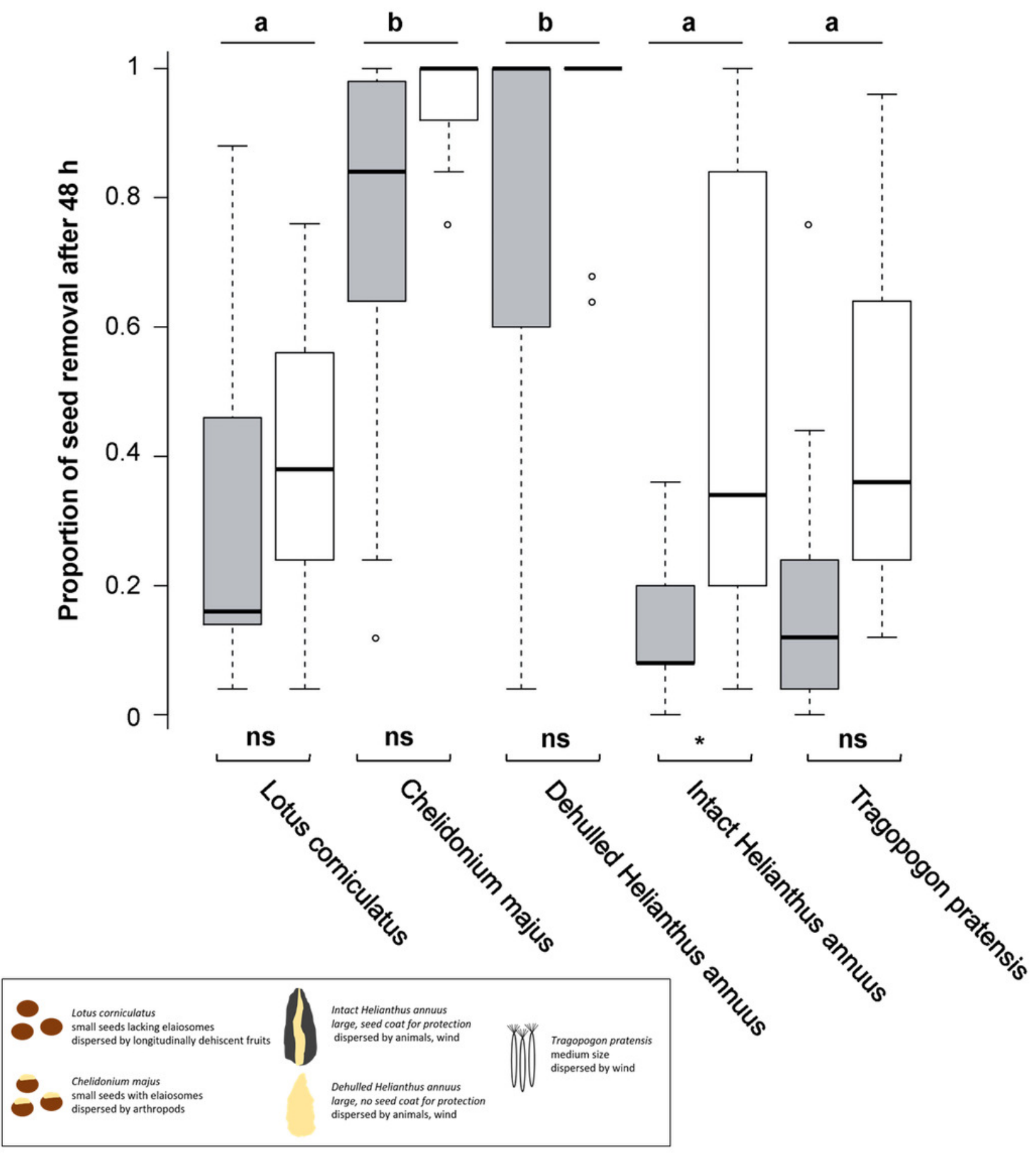


Figure 2

Post-dispersal seed removal over time

48 hours-timescale of seed removal of Lotus corniculatus, Chelidonium majus, dehulled and intact Helianthus annuus and Tragopogon pratensis in forests (a) and grasslands (b) in Darmstadt, and forests (c) and grasslands (d) in Airlenbach. Note the logarithmic scale of the $\mathrm{x}$-axis. The black box summarizes differences in seed traits. 
A.

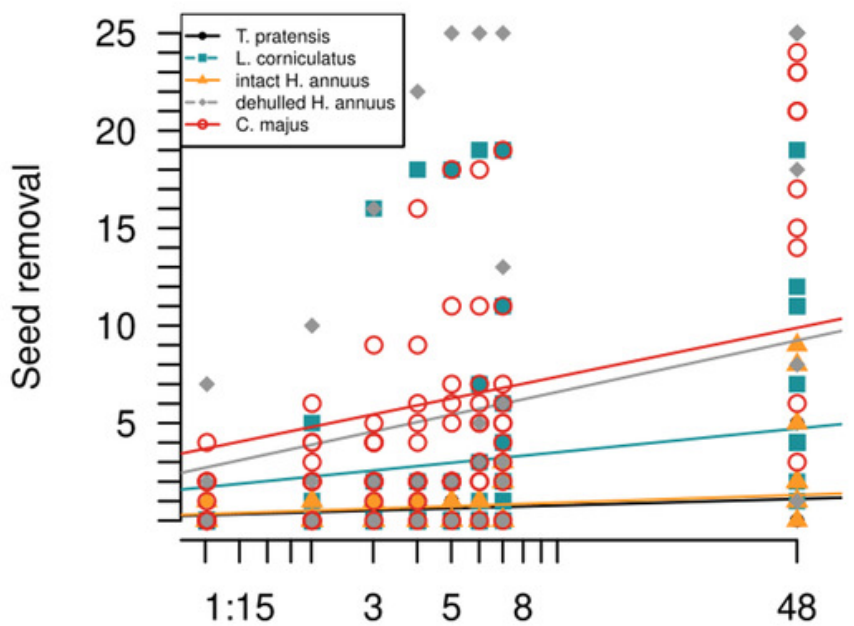

Time [h], Darmstadt forest
B.

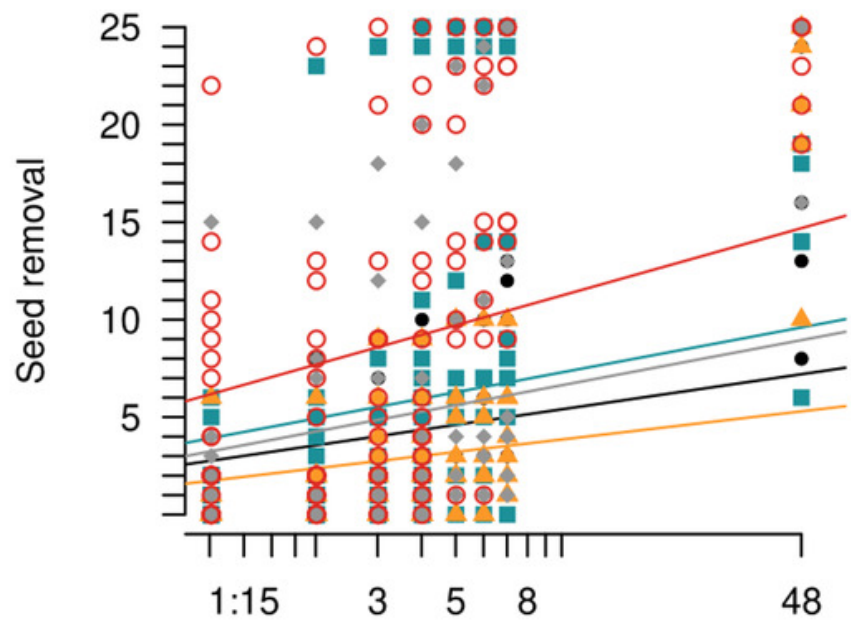

Time [h], Darmstadt grassland

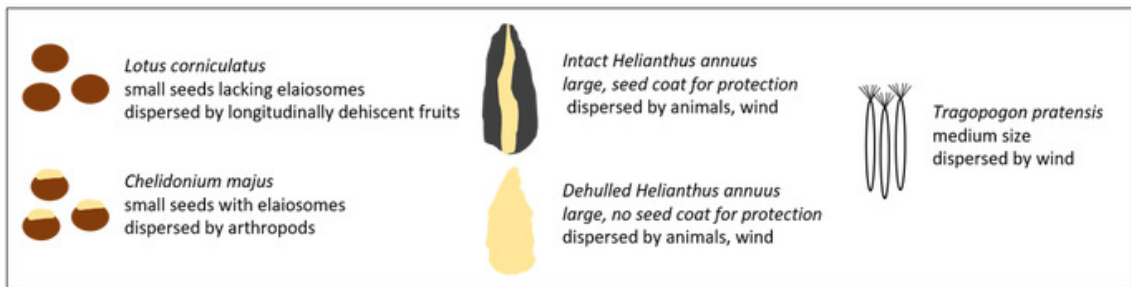

C.

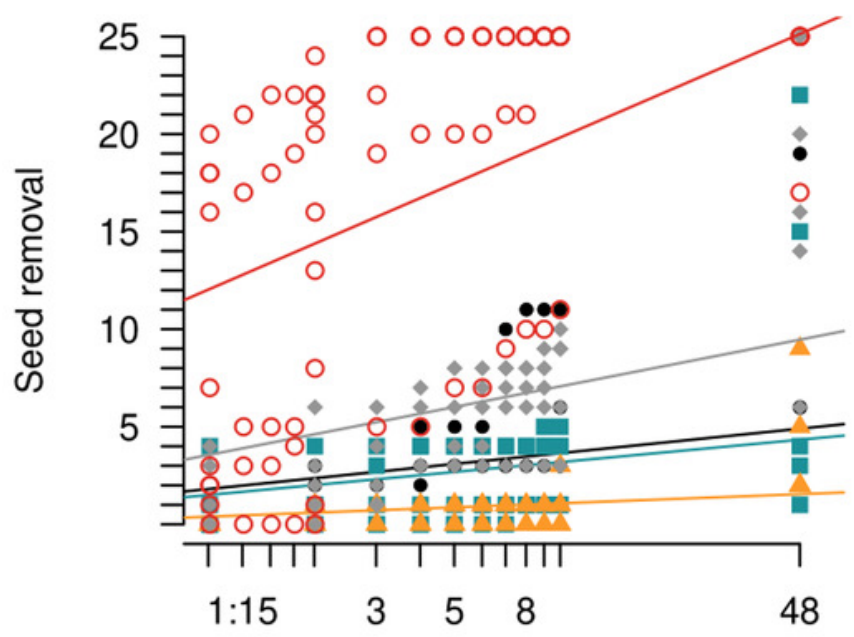

Time [h], Airlenbach forest
D.

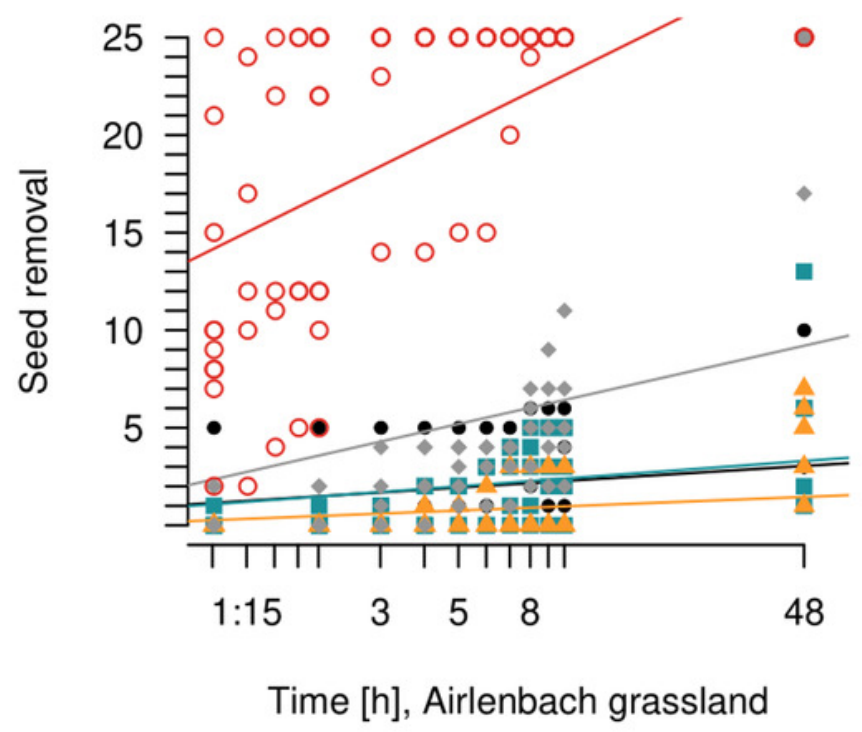


Figure 3

Post-dispersal seed removal and daytime

Removal of seeds of Lotus corniculatus (A), Chelidonium majus (B), dehulled (C) and intact (D) Helianthus annuus at different times of day (day vs night) in forest and grassland sites in Darmstadt, Airlenbach and Zell. Whiskers denote range of data, the black box summarizes differences in seed traits. ${ }^{*}=p<0.05, * *=p<0.02,{ }^{* * *} p<0.01$. 

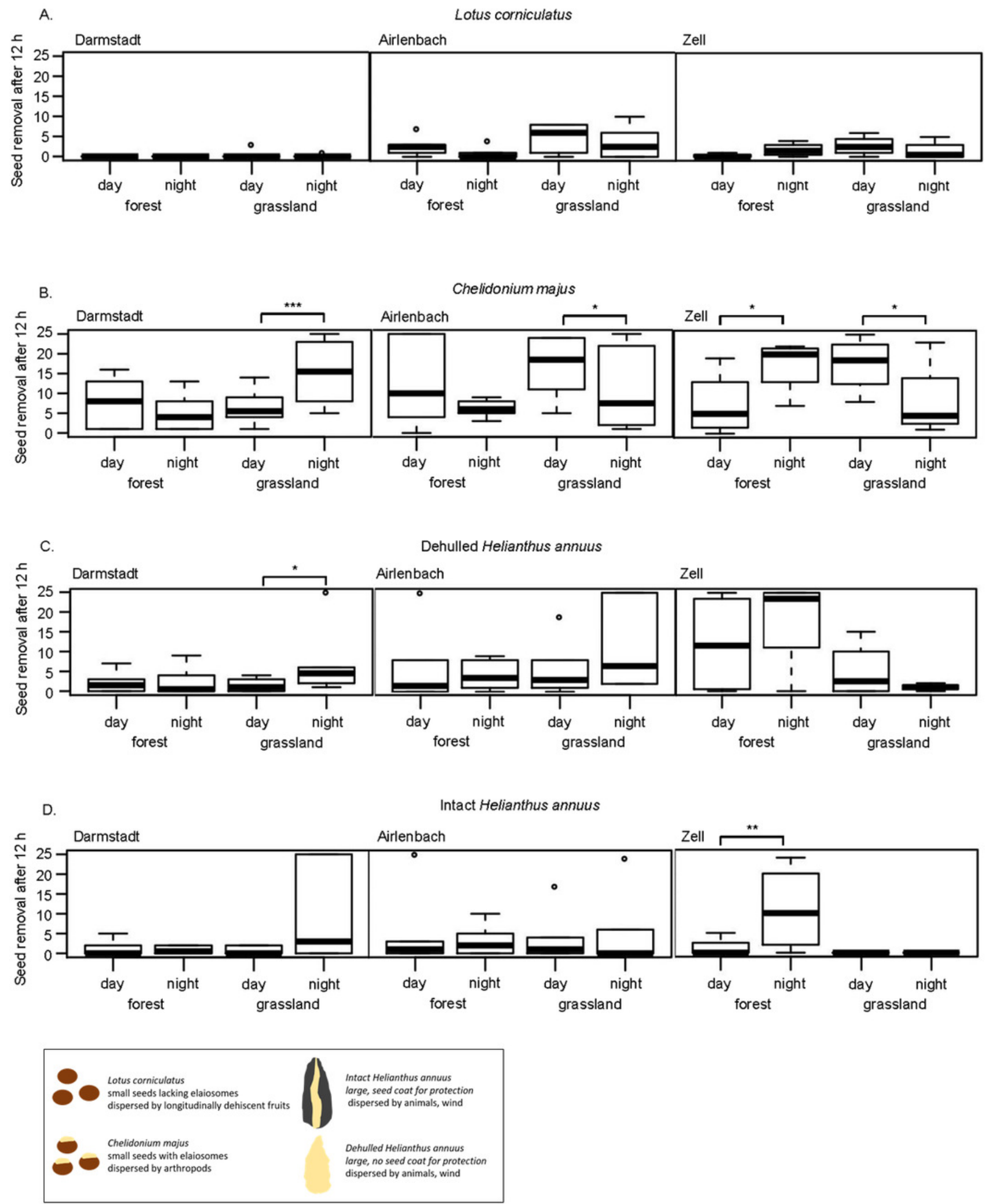